\title{
Analyzing Epistemological Framing of Prospective Physics Teachers on Electromagnetic Understanding Using Hypothetical Debate Problems
}

\author{
Iin Setiani. J \\ Department of Mathematics and Natural Sciences \\ Universitas Tadulako, Palu, Indonesia \\ iinsetianijasmin@yahoo.com \\ Amiruddin Kade \\ Department of Mathematics and Natural Sciences \\ Universitas Tadulako, Palu, Indonesia \\ puangamir@yahoo.com
}

\author{
Darsikin \\ Department of Mathematics and Natural Sciences \\ Universitas Tadulako, Palu, Indonesia
}

\begin{abstract}
This study aimed to describe the shifting of epistemological framing in understanding the electrical magnet concept using a hypothetical debate problem on physics education students. The respondents of the study were nine students of physics education. The instrument used to determine the student epistemological shift framework is problems of understanding the electrical magnet concept that consisted of five items. In the first stage, students are given problems using the conventional thinking-aloud in resolving them. In the second stage, students are given a hypothetical debate about the problems and then the answers from students were analyzed. In the third stage, interviews were conducted to determine the respondents' understanding of concepts in solving the problems. The results showed that the use of hypothetical debate problem may cause a shift that indicated by an increase in the percentage of the qualitative sense-making and quantitative sense-making while on rote equation chasing were not shifted due to the use of it on the students were very good already, in addition to the conceptual understanding and mathematical skills procedures still an obstacle for students in the completion of the electrical magnet subjects.
\end{abstract}

Keywords-epistemological framework; concept understanding; hypothetical debate

\section{INTRODUCTION}

Physics lessons is a learning that does not ignore the nature of physics as a science. The essence of science referred is covering products, processes, and scientific attitude. Learning physics should be able to provide direct experience of the students so that improve their ability to construct, understand, and apply the concepts learned.

Every individual has different characteristics, cognitive abilities, and attitudes. This is what also affects how students solving problems. An expert and novice have their own behavior to play a math information when solving the problems of physics. Research on the behavior of students using mathematics in solving physics problems with different ideas and prior knowledge. Each student has prior knowledge and ideas they bring will use mathematics in the context of physics[1]

In the conventional physics problem, students need answers to solve the physics problem-solving. But when students use hypothetical debate problems in solving physics problem students are given the freedom to sharpen the ideas to determine the right or wrong strategy and find out why or where the wrong strategy is wrong. With the hypothetical debate problems, students are required to compare several problem-solving strategies or the type of reasoning that is often at odds instead of asking students to create their own solutions. By using a hypothetical debate problem make students use strategies that create an imaginary scenario "arguing with colleagues," the student's knowledge will be challenged and re-evaluated. Hypothetical debate problems encourage students to compare strategies in solving physics problems and then the students discuss why they agree or disagree with each of the strategies in physics problem that is provided. The goal: through discussion helps develop students' understanding of what they know, what their friends know and then they will deeply understand the concepts/strategies [2].

Source of epistemology affects how the student feels about the situation and what currently considered and they control the conceptual resources that were brought in problemsolving. Whether students see scientific knowledge as a fixed and absolute or a relative towards one point of view. With a variety of conceptual and epistemological possibilities available, student's thought should also include a process of all possible conceptual and epistemological options then managed to be considered by the individual. This process is called framing [3]. 
Strong and make sense argument of causal mechanisms which epistemology can affect learning give more reason than ever to believe that the epistemological intervention can lead to a better conceptual learning [4]. Epistemology is divided into unproductive epistemology that is thinking just by remembering the formula and obtain numerical answers and productive epistemology that is thinking accompanied by efforts to build an idea by linking the facts and concepts of physics [5].

The general framework used by students in completing the algebra-based physics problems, namely: rote equation chasing, qualitative making dan quantitative sense-making. Rote equation chasing is when students complete a physical problem by inserting quantities into equations of physics that they remembered or memorized. Qualitative sense-making is when students complete a physics problem with the use physics concepts more and use less of mathematical procedures. While quantitative sense-making is a way of solve physics problems where students use mathematical procedures and the concept of physics itself at once[6].

After attending the lecture, many students experiencing misconceptions in magnet electric concept [7]. The majority of students do not understand the topic of electric magnet, and this situation has not changed though after learning [8]. Student conceptual knowledge is a source of knowledge about the method/procedure, but not vice versa. Then the consistency between the two knowledge indicates that contrary to the procedure knowledge, conceptual knowledge has a higher internal consistency [9].

This study aims to investigate the shift of epistemological frame in the understanding of physics concepts on physics education students. This analysis is needed to determine the framework of student epistemology changes in the understanding of physics concepts using a hypothetical debate. Based on the above explanation, the researchers were motivated to conduct research on the analysis of the shifting of the epistemological frame in the understanding of magnet electric concept using hypothetical debate problems on physics education students.

\section{METHOD}

This study is a descriptive-qualitative research where all the data were collected based on the facts obtained in the field. The study is looking more towards the characteristics, qualities, and correlations between activities. Descriptive study is research that does not provide the action, manipulation, or makes a change to the independent variables, but describes the actual state [10]. The study was conducted at the Physics Education Study Program FKIP-UNTAD. The choice of location is based on the consideration that the study program is where the teachers candidate gained the knowledge. Researchers assume this physics study program is the appropriate location to obtain accurate data. The sample in the study was 9 students that consisted of 4 male and 5 female.

The instruments were arranged in the form of subjects description about understanding electric magnet concept. The test consisted of 5 essay items. (1) The thinking-aloud test (TA) in the form of essay problems of electric magnet subjects consist of 5 items. TA was used to collect the data that then analyzed the shifting of the epistemological frame in understanding students' concept of an electric magnet. (2)
Video-camera, which contained footage of respondents' thinking-aloud while answering the TA test. (3) The interview was a kind of semi-structured interviews. This interview digging the depth of student thinking. The position of this interview is to support or reinforce the data obtained that are seeing the shift of epistemological framework.

The analysis of the data in this study carried out during and after data collection. As for the stages of qualitative data analysis activities by Miles and Huberman in Sugyono are (1) reducing the data, (2) presenting data, and (3) conclusion and verification [11].

The data analysis used in the study was non-statistical or qualitative analysis as a percentage. In accordance with the problems that have been formulated so researchers use data analysis to determine the percentage of errors in the student concept of electric magnet subject

The obtained data from the answers will be analyzed in according to the noted research design and use simple statistics which presents the percentage of students' misconception of electric magnets[12].

\section{III.RESULTS AND DISCUSSION}

TABLE I. EPISTEMOLOGICAL FRAMEWORK SHIFTING

\begin{tabular}{|c|l|c|c|c|}
\hline No & $\begin{array}{l}\text { Framewor } \\
\text { k Aspect }\end{array}$ & Conventional & $\begin{array}{c}\text { Hypothetical } \\
\text { Debate } \\
\text { Problems }\end{array}$ & $\begin{array}{c}\text { Epistemologica } \\
\text { I Framework } \\
\text { Shift }\end{array}$ \\
\hline 1 & $\begin{array}{l}\text { Rote } \\
\text { problem } \\
\text { chasing }\end{array}$ & $100 \%$ & $100 \%$ & $0 \%$ \\
\hline 2 & $\begin{array}{l}\text { Qualitative } \\
\text { sense- } \\
\text { making }\end{array}$ & $48,88 \%$ & $75,55 \%$ & $26,67 \%$ \\
\hline 3 & $\begin{array}{l}\text { Quantitativ } \\
\text { e sense- } \\
\text { making }\end{array}$ & $31,11 \%$ & $51,11 \%$ & $20,00 \%$ \\
\hline
\end{tabular}

Epistemological framework explains the expectations of individuals (what is happening) about a situation and then guide how people think and act according to the situation. The epistemological framework emphasizes the interpretation of a person in an event or an ongoing process. An individual will make an epistemological framework based on activity or on their own experience in receiving information. Tuminaro stated that epistemological framework shift was measured with the use of three main frameworks i.e. rote chasing equation, qualitative sense-making and quantitative sensemaking[6].

In problem 1 there is an error and a factor in understanding the concepts of the electric magnet of the respondents. Based on the conventional problem that has been done the findings obtained by researchers was the lack of conceptual understanding by R1, R3, R5, R6, R7, and R8. Respondents' lack of understanding of the concept in describing the correlation graph of force and the square of the distance. Based on these, respondents conceptually not able to describe the correlation between the force and the range square precisely with the grounds that the respondents' understanding in interpreting the equation in the form of a graph is still weak. The results of respondents' answers on problem number 1 indicate that in understanding the concept of Coulomb's force 
particularly in indicator of determining a correlation of force and the quadratic range is to understand graphical form quadratic function because of this misconception respondents are not able to meet the indicators in resolving the physics problem. The factors that caused the mistakes made by respondents was the lack of understanding in applying mathematics to describe the graph in a quadratic function properly. This error is due to the inability of the respondents in solving the problem from an interpretation of the equation into the form of a graph.

In the hypothetical debate problems, respondents expressed their understanding of the solutions provided by the researcher at the time of hypothetical debate problems. During the debates, respondents taking two solutions that are believed to be true and ignore other solutions. Two of these solutions debated and resulting that the right solution is used in number 1 is the solution B. In problem number 1, group 1, group 2 and group 3 chose the same solution, namely a solution B with an understanding and the range $(r)$ is far then the tensile force $(F)$ weakening so the graph of force $(F)$ and range (r) is not straight but slightly curved downward as a quadratic function range.

After doing a hypothetical debate problems, then there was a shift in R1, R3, R5, R6, R7, and R8. The shift that occurs in the framework of qualitative sense-making and quantitative sense-making while on framework rote chasing equation did not shift. The shift in the framework of qualitative sensemaking and quantitative sense-making was influenced by an understanding of the concept of fellow debates who capable of expressing the owned concept properly and better that was able to encourage co-debate who was still have lack of understanding of the concepts and mathematical procedures able to shifted towards the positive with a more precise understanding of the concepts. For rote equation chasing was not shifted due to respondents understanding on the framework of rote equation chasing was already very good, indicated by proper understanding on the use of physics symbols.

In problem number 2 in order to resolve the problem appropriately respondent should be able to master the concepts in determining the quantity of charge on the ball that has mass. Based on the results of thinking aloud $R_{1_{2}}, R_{2_{2}}, R_{3_{2}}, R_{4_{2}}, R_{5_{2}}$, $R_{6_{2}}, R_{7_{3}}$, and $R_{8_{3}}$ there are some mistakes that can hinder the problem-solving. The findings of the mistakes made by the respondent $R_{1_{2}}, R_{2_{2}}, R_{3_{2}}, R_{4_{2}}, R_{5_{2}}, R_{6_{2}}, R_{6_{2}}, R_{7_{2}}$, and $R_{8_{2}}$ as follows. $R_{1_{2}}$ considered that to solve the number 2 only requires equation $F_{\text {listrik }}$ without reviewing that the ball has mass. Respondents do not understand this concept so that there is an error on problem-solving. The results of respondents' answers on problem number 2 indicate that in understanding the concept to a quantity of charge on the hanging-ball requires the ability to understand the equations related to the problems. These lack of understanding of the concept that led to the respondent who was unable to meet the indicators in solving problem 2.

Respondents did a quite long debate to understand the proper equation to resolve the problems appropriately. In the hypothetical debate problems of respondents express a concept owned but there are two respondents did not agree with the other respondents because they think they have the most appropriate concept. $R_{1_{2}}, R_{3_{2}}, R_{4_{2}}, R_{5_{2}}, R_{6_{2}}, R_{7_{2}}$, and $R_{8_{2}}$ agreed that to solve the problem number 2 is very likely used $F_{\text {listrik }}=F_{\text {Gravitasi }}$, without seeing the influence of rope tension that caused it to balance. For the respondent $R_{2_{2}}$ and $R_{9_{2}}$ to solve the number 2 should review the tension of rope which used to hang the ball.

After conducting a hypothetical debate problems, there was no shifting of the epistemological framework in respondents $R_{1_{2}}, R_{3_{2}}, R_{4_{2}}, R_{5_{2}}, R_{6_{2}}, R_{7_{2}}$, and $R_{8_{2}}$ in the three main frameworks used rote chasing equation, qualitative sense-making and quantitative sense-making. This happened because the respondents had misconceptions to determine the charge on the ball that has mass. The absence of a shift in the epistemological framework at the time of the hypothetical debate problems and after the interview can be seen that there was a misconception among respondents.

On problem 3 requires an understanding of the concept of an electric field. Based on the results of thinking aloud there were inadequate understanding of concepts of respondents $R_{3_{3}}, R_{4_{3}}, R_{6_{3}}, R_{7_{3}}$, and $R_{8_{3}}$ in solving problems. The findings of the lack of understanding of the physics concepts in the completion of problem 3 as follows: lack of understanding of the concept by $R_{33}$ who stated that Coloumb's force and the electric field are the same. The result of the respondent's answers to the problem number 3 shows that the weakness of the respondents understanding to the concept of the electric field in the indicator for determining the point that has zero electric fields. The factor causing the respondent error is the inability of the respondent in determining the precise physics equations to solve the problems.

After conducting a hypothetical debate problems for problem 3 , there were shifts on $R_{4_{3}}, R_{6_{3}}, R_{7_{3}}$, and $R_{8_{3}}$. The shift of $R_{4_{3}}$ in the framework of qualitative sense-making and quantitative sense-making. On $R_{43}$ the shifting of the two frameworks qualitative sense-making and quantitative sensemaking is caused by the reactivation of understanding after held the hypothetical debate problem. This is consistent with research by Lising and Elby, stated that epistemology as ideas that emerge in students' knowledge and learning experiences. For the respondents $R_{6_{3}}, R_{7_{3}}$ and $R_{8_{3}}$ the shifting was on the qualitative sense-making framework. This is influenced by a conceptual presentation given by co-debate, but on the respondents $R_{6_{3}}, R_{7_{3}}$, and $R_{8_{3}}$, there was no shifting sense of the quantitative sense-making framework. These results are supported by research by Ataide and Greca, this study shows students, in general, have failed to fully reflect the scientific concept, even though they may have learned about these concepts throughout formal secondary school education and seemed to have little difficulty implementing notation and mathematical procedures [13]. On the respondents $R_{33}$ did not experience a shift after the hypothetical debate problem. This is caused by misconceptions made by the respondent $R_{3_{3}}$ in the problem to determine electricity field equal to zero.

Problem number 4 talks about dynamic electricity. At the process of completion of problem 4, the conceptual understanding is needed, other than that the respondent is required to know the understanding of the current flowing in the circuit. In problem number 4 there are errors found by the researchers. Based on the test results thinking aloud that have been made there were misconceptions on the respondents $R_{4}$, 
$R_{6}$ and $R_{7_{4}}$ in solving the problems. The finding of fault concepts of physics in the completion of problem 4 as follows: a misconception that does consider that to determine the current flowing in the current two by dividing the difference potential with two barriers in series. The results of respondents' answers on problem number 4 show the weakness of the respondent's understanding of the concept of dynamic electricity. This leads to the inability of respondents in solving problem number 4. In problem number 4 respondents should first determine the parallel barrier then determine the total resistance obtained after totals obstacle then determine the total flow using Ohm's law equation. Factors causing the respondent error was lack of understanding of dynamic electricity concept. Lack of understanding of this concept led to the respondent was unable to resolve the problem appropriately.

After conducting a hypothetical debate problem there is a shift in the epistemological framework on $R_{6_{4}}$. The shift on $R_{64}$ on the qualitative sense-making framework but in the quantitative sense-making framework did not shift. The shift in respondents' qualitative sense-making framework caused by the understanding that has been owned and honed at the time of the hypothetical debate problems with expressing concepts in problem-solving. $R_{4_{4}}$ and $R_{6_{4}}$ did not shift the framework although quantitative sense-making and even the qualitative sense-making framework has been very good. This is affected by the difficulties of respondents in the use of mathematics in physics this result is consistent with research by Tuminaro and Redish stated that the difficulties of using mathematics in physics experienced by students generally from two factors, namely (1) the lack of math skills needed to solve problems and (2) the student does not know how to apply math skills possessed[14]. On the respondents $R_{74}$ did not experience a shift after the hypothetical debate problem. This is caused by misconceptions made by respondent $R_{74}$.

Problem number 5 discusses the concept of magnetic fields. In the problem-solving process of problem 5 required a conceptual understanding of the magnetic field and the vector unit. In problem number 5 there were errors found by the researchers. Based on the test results thinking aloud has done an inadequate understanding of the concept of the respondent $R_{15}, R_{25}, R_{35}, R_{45}, R_{5_{5}}, R_{65}, R_{7_{5}}$, and $R_{8_{5}}$ in solving problems. The results of respondents' answers on problem number 5 showed that the weakness of the respondents in understanding the concept of a magnetic field and determines the vector unit. In addition, respondents had difficulty in determining the exact equation used to solve problem number 5. Factors caused respondents' errors are lack of understanding of the magnetic fields. Errors in determining the vector unit were also one factor in solving the inability of the respondent on a magnetic field.

These results indicate that the use of a hypothetical debate problems can cause a shift positively marked by an increase in the percentage of the qualitative and quantitative sensemaking sense-making while on rote equation chasing not shifted due to the use of rote equation chasing the forces of physics students in 2014 has been very good.

After conducting a hypothetical debate problems on there is a shift in the epistemological framework of $R_{1_{5}}, R_{2}, R_{3_{5}}, R_{4_{2}}, R_{5_{5}}, R_{65}$, and $R_{8_{5}}$. In problem number 5 qualitative sense-making frame shift occurred on the respondents $R_{1_{5}}, R_{2_{5}}, R_{35}, R_{4_{2}}, R_{5_{5}}, R_{6_{5}}$, and $R_{8_{5}}$ but there was no shifting in a quantitative sense-making framework. The difficulty of respondents in the use of mathematics in physics was the constraints that respondents had difficulty in solving correctly although understanding of the concept of the respondents was correct. Mathematics has an important role for respondents to solve the physics problems. In the respondent $R_{35}$ and $R_{45}$, there was no shifting in qualitative sense-making and quantitative sense-making. This is influenced by misconceptions of respondent $R_{35}$ and $R_{75}$. Respondents had difficulty in understanding the concepts of physics and use math in physics. These results are consistent with studies of Al-Omari and Maqdadi that showed students, in general, have failed to fully reflect the scientific concept. Although they may have learned about these concepts throughout the formal secondary school education and seemed to have little difficulty applying mathematical notation and procedures.

Based on the results the percentage of respondents in the three epistemological frameworks can be seen in Figure 1

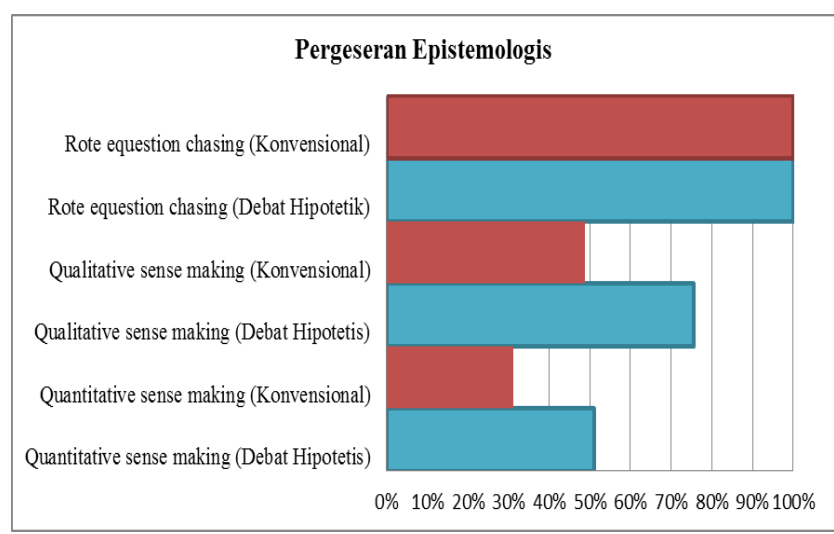

Fig. 1. Shifting diagram of epistemology framework

These results indicate that for framework rote equation chasing respondents had very good as being able to master the use of physics symbols properly when given either conventional or hypothetical debate problem. It is caused by a general understanding that the student has mastered the physics symbols appropriately. In the framework of qualitative sense-making obtained a percentage of $48.88 \%$ for a conventional problem and $75.55 \%$ for hypothetical debate problem. These results indicate that there was a $26.67 \%$ shift in the framework of qualitative sense-making. The percentage of $26.67 \%$ due to a discussion among the respondents expressed the opinion of each respondent at the time of the hypothetical debate problems based on the concept that is owned and explored the concept of due administration of the solution during the debate.

In the framework of quantitative sense-making obtained a percentage of $31.11 \%$ for the conventional problem and $51.11 \%$ for hypothetical debate problem. These results indicate that there was a $20.00 \%$ shift in the framework of the quantitative sense-making and the result is smaller than the $26.67 \%$ shift in the framework of qualitative sense-making, it is influenced by students understand the concepts of physics, but it is difficult for them to settle in mathematics. These results are supported by research of Ataide and Greca that 
students, in general, have failed to fully reflect the scientific concept, even though they may have learned about these concepts throughout the formal secondary school education and seemed to have little difficulty applying mathematical notation and procedures.

\section{CONCLUSION}

Based on the analysis and discussion of the results of this study concluded the following matters.

Epistemological framework of teachers candidate students in magnetic electric subjects showed a shifting by using a hypothetical debate problems. The shift in the framework of rote equation chasing was $0 \%$, a shift in the framework of qualitative sense-making was $40 \%$ and a shifting in the framework of quantitative sense-making was $35.56 \%$. These results indicate that the use of a hypothetical debate problems can cause a shift positively marked by an increase in the percentage of the qualitative sense-making and quantitative sense-making while on rote equation chasing was not shifted due to the use of rote equation chasing by the students was in very good.

\section{REFERENCE}

[1] T. J. Bing and E. F. Redish, "The Cognitive Blending of Mathematics and Physics Knowledge," Dep. Physics, Univ. Maryland, Coll. Park, pp. 1-4, 2007.

[2] D. Hu and N. S. Rebello, "Characterizing Student Use Of Differential Resources In Physics Integration Problems," Phys. Rev. Spec. Top. Phys. Educ. Res., vol. 10, no. 10117, 2014.

[3] T. J. Bing and E. F. Redish, "Analyzing problem-solving using math in physics : Epistemological framing via warrants," Phys. Rev. Spec. Top. Educ. Res., vol. 5, no. 2, pp. 1-15, 2009.

[4] L. Lising and A. Elby, "The impact of epistemology on learning: A case study from introductory physics," Am. J. Phys., vol. 73, no. 4, 2005.

[5] Hodges, R. A. 2003. "Physicists Epistemologies of Quantum Mechanics". AAPT Summer Meeting. Madison. Wisconsin.

[6] J. Tuminaro, “A COGNITIVE FRAMEWORK FOR ANALYZING AND DESCRIBING INTRODUCTORY STUDENTS ASE AND UNDERSTANDING OF MATHEMATICS IN PHYSICS," Thesis, Univ. Maryland., no. 1, 2004.

[7] P. V Engelhard and R. J. Beichner, "Students' understanding of direct current resistive electrical circuits," Dep. Physics, North Carolina State Univ., vol. 72, no. 1, pp. 98-115, 2004.

[8] Narjaikaew, P., Emarat, N., Arayathanakul, K. \& Cowie, B. (2005) "Year-1 Thai University Students' Conceptions of Electricity and Magnetism". Physics Educational Network of Thailand (PENThai) and The Centre for Science and Technology Education Research (CSTER). 10. (3). 109-114. [9] Schneider, M. and Stern, E. 2010. Conceptual and Procedural Knowledge of a Mathematics Problem Their Measurement. Melalui <http://www. psych.unito.it/csc/cogsci05/frame/talk/f610-schneider.pdf> [11/3/2016].

[9] Sukmadinata, N. (2010). Metode Penelitian Pendidikan. Bandung: PT Remaja Rosdakarya.

[10] Sugiyono. 2008. Metode penelitian kuantitatif kualitatif dan R \& D. Bandung: Alfabeta.

[11] Sudjana, Nana. (2011).Penilaian Hasil Proses Belajar. Bandung: PT Remaja Rosdakarya.

[12] Atarde, A. R. P. and Greca, I. M. (2013). Epistemic Views of the Correlation Between Physics and Mathematics: Its Influence on the Approach of Undergraduate Students to Problem Solving. Springer Science+Business Media B.V. 2012. E-journal Sci \& Educ. 22:14051421.

[13] Redish, E. F., Scherr, R. E., Tuminaro, J. (2006). "Reverse Elby, A., \& Hammer, D. (n.d.). Epistemological resources and framing: A cognitive framework for helping teachers interpret and respond to their students ' epistemologies, (3), 1-32.
[14] E. F. Redish, R. E. Scherr, and J. Tuminaro, "Reverse engineering the solution of a 'simple' physics problem: Why learning physics is harder than it looks," Maryl. Phys. Educ. Res. Gr. Many Useful Discuss. Suggest., pp. 1-9, 2005. 